\title{
The effects of fatigue, pain, and depression on quality of life in ischemic stroke patients: The Bergen Stroke Study
}

This article was published in the following Dove Press journal:

Vascular Health and Risk Management

26 June 2012

Number of times this article has been viewed

\section{Halvor Naess' \\ Lene Lunde ${ }^{2}$ \\ Jan Brogger'}

'Department of Neurology, Haukeland University Hospital, ${ }^{2}$ Department of Economics, University of Bergen, Bergen, Norway
Background: Many patients with cerebral infarction suffer from symptoms such as pain, fatigue, and depression. The aim of this study was to evaluate these symptoms in relation to health-related quality of life (HRQoL) on long-term follow-up.

Materials and methods: All surviving stroke patients admitted to the Stroke Unit, Haukeland University Hospital, Norway between February 2006 and November 2008 were sent a questionnaire, including a visual analog pain scale, Fatigue Severity Scale, Depression Subscale of Hospital Anxiety and Depression Scale, Barthel Index, and three measures of HRQoL - 15D, EuroQol, and EuroQol Visual Analogue Scale - at least 6 months after stroke onset. Cox regression survival analysis, including EQ-5D, was performed by November 2009.

Results: The questionnaire was returned by 328 patients. All three symptoms were reported by $10.1 \%$ of the patients, and $26 \%$ reported two symptoms. There was a significant association between worse HRQoL scores and an increasing number of cooccurring symptoms for all three HRQoL scores. Fatigue, depression, pain, functional state, and sleeping disorder on follow-up accounted for $58 \%-83 \%$ of the variability in HRQoL, depending on which HRQoL scale was used. Cox regression analysis showed that mortality was associated with a low EuroQol score $(P=0.016)$.

Conclusion: Pain, fatigue, and depression were common symptoms among these stroke patients and, to a large extent, they determined the patients' HRQoL. Low HRQoL was associated with increased mortality.

Keywords: cerebral infarction, symptoms, mortality

\section{Introduction}

In addition to neurological and cognitive deficits, many patients with cerebral infarction report subjective symptoms, including pain, depression, and fatigue. In contrast to depression, until recently, pain and fatigue have been neglected issues in studies of patients with cerebral infarction. ${ }^{1,2}$ Major depression occurs among $15 \%-20 \%,{ }^{3,4}$ fatigue among $40 \%, 5,6$ and pain among $20 \%-50 \%{ }^{7-9}$ of patients with cerebral infarction, on follow-up. Most studies have focused on single symptoms; however, these symptoms often occur together.

A symptom cluster has been defined as two or more symptoms that tend to occur together. "Relationships among symptoms within a cluster should be stronger than relationships among symptoms across different clusters. Symptoms in a cluster may or may not share a common etiology."10

There have been few studies of single and symptom clusters and health-related quality of life (HRQoL) in patients with cerebral infarction. 
The cluster of pain, fatigue, and depression has previously been studied in cancer patients. ${ }^{11}$ The aim of this study, therefore, was to evaluate the symptom cluster of pain, fatigue, and depression on follow-up in relation to HRQoL among patients with cerebral infarction and to evaluate prognostic factors for HRQoL. We hypothesized that co-occurring symptoms adversely affect HRQoL.

\section{Materials and methods Patients}

All consecutive patients with acute cerebral infarction (index stroke) admitted to the Stroke Unit, Department of Neurology, Haukeland University Hospital, between February 2006 and July 2008, were prospectively registered in a database (The Bergen Stroke Registry). Cerebral infarction was defined in accordance with the BaltimoreWashington Cooperative Young Stroke Study Criteria, comprising neurological deficits lasting more than 24 hours due to ischemic lesions or transient ischemic attacks, where computed tomography (CT) or magnetic resonance imaging (MRI) showed infarctions related to the clinical findings. ${ }^{12}$

All patients had undergone CT or MRI. The National Institute of Health Stroke Scale was used to assess stroke severity on admission, and a modified Rankin Scale (mRS) score was obtained seven days after stroke onset (or earlier, if the patient was discharged sooner). Diagnostic workup included electrocardiogram, Holter monitoring, echocardiography, and Duplex sonography of neck vessels.

Risk factors, including hypertension, smoking, diabetes mellitus, myocardial infarction, angina pectoris, peripheral artery disease, atrial fibrillation, and preadmission depression, were registered on admittance. Preadmission depression was defined as depression requiring use of a selective serotonin reuptake inhibitor any time before stroke onset. Hypertension was defined as prior use of antihypertensive medication. Current smoking was defined as smoking at least one cigarette per day. Diabetes mellitus was considered present if the patient was on a glucoselowering diet or medication. Angina pectoris, myocardial infarction, and peripheral artery disease were considered present if diagnosed by a physician at any time before stroke onset. Atrial fibrillation required electrocardiogram confirmation any time prior to stroke onset. A history of prior stroke was registered. Etiology of ischemic stroke was determined by the Trial of Org 10172 in Acute Stroke Treatment classification. ${ }^{13}$
Table I Characteristics of responders and nonresponders

\begin{tabular}{|c|c|c|c|}
\hline & $\begin{array}{l}\text { Responders } \\
\mathbf{n}=\mathbf{3 2 8}\end{array}$ & $\begin{array}{l}\text { Nonresponders } \\
n=213\end{array}$ & $P$ \\
\hline Age & 67.7 & 69.0 & 0.30 \\
\hline $\begin{array}{l}\text { NIHSS score on admission, } \\
\text { mean }\end{array}$ & 4.3 & 6.0 & $<0.001$ \\
\hline mRS, median & I & 2 & $<0.001$ \\
\hline \multirow[t]{2}{*}{ Barthel Index score, mean } & 92 & 79 & $<0.001$ \\
\hline & n (\%) & n (\%) & \\
\hline Female & $122(37)$ & $96(45)$ & 0.07 \\
\hline Prior depression & $47(18)$ & $30(18)$ & 0.80 \\
\hline Married & $208(66)$ & $119(58)$ & 0.07 \\
\hline Employed & $109(36)$ & $54(28)$ & 0.06 \\
\hline Prior stroke & $64(20)$ & $48(23)$ & 0.45 \\
\hline Prior myocardial infarction & $38(12)$ & $21(10)$ & 0.57 \\
\hline Diabetes mellitus & $31(10)$ & $31(15)$ & 0.07 \\
\hline Hypertension & $167(52)$ & $110(52)$ & 1.00 \\
\hline Smoking & $76(24)$ & $60(30)$ & 0.18 \\
\hline
\end{tabular}

Note: mRS scores were obtained on day seven or upon discharge, if discharged earlier.

Abbreviations: NIHSS, National Institute of Health Stroke Scale; mRS, modified Rankin Scale.

All living patients received a postal questionnaire at least 6 months after stroke onset. Patients were asked, "Do you suffer from pain?" If the answer was "yes," they were asked to grade pain intensity from 0 (no pain) to 10 (worst possible pain) (visual analog scale). The questionnaire included the Fatigue Severity Scale (FSS), ${ }^{14}$ Depression Subscale of the Hospital Anxiety and Depression Scale (HADS-D), ${ }^{15}$ EuroQol (EQ-5D), 15D, Barthel Index (BI), and a question about sleeping disturbances (no or slight disturbances versus moderate or severe sleeping disturbances, based on the sleep subscore of 15D). Postal reminders were sent to nonresponders once. Post-stroke fatigue was defined as FSS score $\geq 5 .{ }^{16}$ FSS was chosen because it has been validated in stroke patients. ${ }^{17}$ Post-stroke depression was defined as HADS-D $\geq 8 .{ }^{18} \mathrm{HRQoL}$ was assessed by

Table 2 Quality of life on follow-up in patients with cerebral infarction

\begin{tabular}{ll}
\hline Follow-up & \\
EQ-5D*, median (IQR), $\mathrm{n}=278$ & $0.74(0.62-0.88)$ \\
I5D, median (IQR), $\mathrm{n}=266$ & $0.86(0.74-0.93)$ \\
EQ-VAS, median (IQR), $\mathrm{n}=278$ & $7(5-8)$ \\
Pain $\mathrm{n}(\%), \mathrm{n}=328$ & $157(48 \%)$ \\
FSS, median (IQR), $\mathrm{n}=307$ & $4.8(3-5.8)$ \\
Sleeping disturbances, $\mathrm{n}(\%), \mathrm{n}=326$ & $87(27)$ \\
Depression HADS-D $>=8, \mathrm{n}(\%), \mathrm{n}=3 \mathrm{I}$ I & $6 \mathrm{I}(20)$ \\
Barthel Index score, median (IQR), $\mathrm{n}=288$ & $100(95-100)$ \\
\hline
\end{tabular}

Abbreviations: EQ-5D, EuroQol; IQR, interquartile range; EQ-VAS, EuroQol Visual Analogue Scale; FSS, Fatigue Severity Scale; HADS-D, Depression Subscale of the Hospital Anxiety and Depression Scale. 
EQ-5D and 15D. EQ-5D is a generic HRQoL measure that consists of five specific questions regarding mobility, selfcare, pain/discomfort, usual activities, and anxiety/depression. Each of these attributes has three answer categories with three different levels: no problem, some problem, and major problem. $15 \mathrm{D}$ is a generic, 15-dimensional, standardized, self-administered measure of HRQoL, which can be used as a profile and single index score measure. ${ }^{19}$ Finally, the patients were asked to demonstrate their general state of health using the EuroQol visual analogue scale (EQ-VAS). The worst imaginable health state has a value of 0 , and the best imaginable health state has a value of 10 .

The study was approved by the local ethics committee, and informed consent was obtained from all patients.

\section{Statistics}

Logistic regression analysis, linear regression analysis, chi-square test, Fisher's exact test, pair-wise correlation test, and Student's $t$-test were performed when appropriate. FSS, HADS-D, pain (VAS), EQ-5D, EQ-VAS, 15D, and $\mathrm{BI}$ were used only if the patients had completed all corresponding questions. Cox regression analysis for survival after the return of the questionnaire was performed by November 2009 (representing a second follow-up for survival only). STATA 11.0 was used for the analyses.

\section{Results}

A total of 514 living cerebral infarction patients received the questionnaire, and 328 patients returned it (response rate $61 \%$ ). Mean time from index stroke to follow-up was 372 days ( $\mathrm{SD}=138$, range $185-757$ days). The questionnaire was completed by $80 \%$ of the patients, whereas $20 \%$ needed assistance from family members or friends. The demographics of the responders and non-responders are shown in Table 1. Table 2 shows the HRQoL results of the responders. The mean EQ-5D total score was $0.70(\mathrm{SD}=0.30)$; the median was 0.74 (interquartile range $0.62-1$ ). The mean $15 \mathrm{D}$ score was $0.82(\mathrm{SD}=0.14)$; the median was 0.86 (interquartile range $0.74-1)$. The mean EQ-VAS score was $6.6(\mathrm{SD}=2.1)$; the median was 7 (interquartile range 5-8).

Complete data on depression, fatigue, and pain were available for 296 (54.7\%) patients. Depression was disclosed

Table 3 Pair-wise correlation of different variables with EQ-VAS, EQ-5D total, and I5D in patients with cerebral infarction

\begin{tabular}{|c|c|c|c|c|c|c|}
\hline \multirow[t]{2}{*}{ Clinical variables } & \multicolumn{2}{|l|}{$\begin{array}{l}\text { EQ-VAS } \\
n=278\end{array}$} & \multicolumn{2}{|l|}{$\begin{array}{l}\text { EQ-5D } \\
n=279\end{array}$} & \multicolumn{2}{|l|}{$\begin{array}{l}\text { I5D } \\
n=266\end{array}$} \\
\hline & Pair-wise correlation & $P$-value & Pair-wise correlation & $P$-value & Pair-wise correlation & $P$-value \\
\hline Sex & -0.11 & 0.06 & -0.14 & 0.009 & -0.13 & 0.03 \\
\hline Age & -0.18 & 0.003 & -0.15 & 0.006 & -0.22 & $<0.001$ \\
\hline \multicolumn{7}{|c|}{ During hospital stay } \\
\hline Prior depression & -0.37 & $<0.001$ & -0.34 & $<0.001$ & -0.41 & $<0.001$ \\
\hline Prior stroke & -0.16 & 0.01 & -0.10 & 0.10 & -0.16 & 0.01 \\
\hline $\begin{array}{l}\text { Prior myocardial } \\
\text { infarction }\end{array}$ & 0.01 & 0.83 & 0.01 & 0.80 & -0.08 & 0.18 \\
\hline Diabetes mellitus & -0.05 & 0.45 & -0.02 & 0.78 & 0.05 & 0.44 \\
\hline Smoking & -0.09 & 0.20 & -0.12 & 0.04 & -0.01 & 0.92 \\
\hline Hypertension & -0.09 & 0.15 & -0.09 & 0.12 & -0.01 & 0.89 \\
\hline Married & 0.16 & 0.01 & 0.15 & 0.007 & 0.17 & 0.006 \\
\hline Employed & 0.19 & 0.002 & 0.14 & 0.01 & 0.21 & 0.001 \\
\hline mRS day 7 & -0.33 & $<0.001$ & -0.42 & $<0.00$ I & -0.38 & $<0.00$ I \\
\hline $\begin{array}{l}\text { Barthel Index } \\
\text { score, day } 7\end{array}$ & 0.34 & $<0.001$ & 0.44 & $<0.001$ & 0.43 & $<0.001$ \\
\hline \multicolumn{7}{|l|}{ Follow-up } \\
\hline Pain VAS & -0.43 & $<0.001$ & -0.57 & $<0.001$ & -0.53 & $<0.001$ \\
\hline HADS-D & -0.62 & $<0.001$ & -0.61 & $<0.001$ & -0.77 & $<0.001$ \\
\hline FSS & -0.64 & $<0.001$ & -0.46 & $<0.001$ & -0.60 & $<0.001$ \\
\hline Barthel Index score & 0.53 & $<0.001$ & 0.67 & $<0.001$ & 0.67 & $<0.001$ \\
\hline Sleep disturbances & -0.27 & $<0.001$ & -0.33 & $<0.001$ & -0.41 & $<0.001$ \\
\hline EQ-VAS & - & - & 0.67 & $<0.00$ I & 0.79 & $<0.00$ I \\
\hline EQ-5D & 0.67 & $<0.001$ & - & - & 0.76 & $<0.001$ \\
\hline I5D & 0.79 & $<0.001$ & 0.76 & $<0.001$ & - & - \\
\hline
\end{tabular}

Abbreviations: EQ-VAS, EuroQol Visual Analogue Scale; EQ-5D, EuroQol; mRS, modified Rankin Scale; VAS, visual analog scale; HADS-D, Depression Subscale of the Hospital Anxiety and Depression Scale; FSS, Fatigue Severity Scale. 

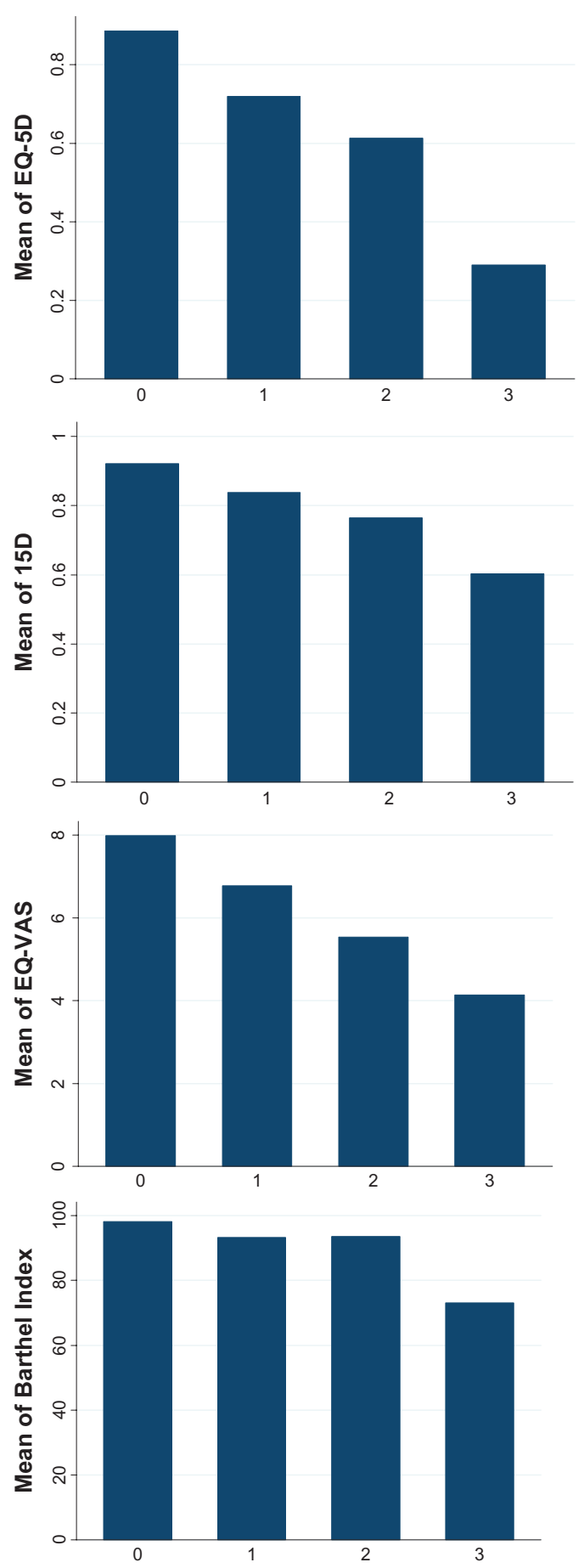

Figure I Quality of life at follow-up in relation to none, one, two, or three of the symptoms (pain, fatigue, and depression) in patients with cerebral infarction. Abbreviations: EQ-VAS, EuroQol Visual Analogue Scale; EQ-5D, EuroQol.

by $55(20.6 \%)$, fatigue by $134(45.3 \%)$, and pain by 146 $(49.3 \%)$ of the stroke patients. Of all the 296 patients, 30 (10.1\%) reported all three symptoms. Pain and fatigue, but no depression, were reported by 58 (19.6\%) patients. Pain and depression, but no fatigue, were reported by $6(2.0 \%)$ patients. Depression and fatigue, but no pain, were reported by $13(4.4 \%)$ patients. Among 198 patients with symptoms, 107 (54\%) had more than one symptom.

Table 3 shows pair-wise correlation between different variables and EQ-5D, 15D, and EQ-VAS. There was high correlation between FSS, HADS-D, pain VAS, and all HRQoL scores.

Figure 1 shows the mean results of EQ-5D, 15D, EQ-VAS, and $\mathrm{BI}$ in groups, according to the number of symptoms. Linear regression analyses, with EQ-5D, 15D, and EQ-VAS as dependent variables, showed partial correlation, ranging from -0.51 to -0.69 (all $P<0.001$ ), for a variable representing the frequency of pain, fatigue, and depression in each patient (0-3) at follow-up, after adjusting for age, sex, and BI.

Table 4 shows the results of linear regression analyses, with EQ-5D, 15D, and EQ-VAS as dependent variables. Highest partial correlations were found for BI and pain as to EQ-5D, for BI and HADS-D as to 15D, and for BI and FSS as to EQ-VAS. The independent variables accounted for $65 \%$ of the variability in EQ-5D scores, $83 \%$ of the variability in $15 \mathrm{D}$ scores, and $58 \%$ of the variability in EQ-VAS scores.

Table 5 shows the results of linear regression analysis, with EQ-5D, 15D, and EQ-VAS as dependent variables and variables known at the time of the index stroke. Lower HRQoL scores, as measured by all three scales, were associated with advanced age, prior stroke, prior depression, smoking, and lower BI seven days after stroke onset. The independent variables accounted for $36 \%$ of the variability in EQ-5D scores, $31 \%$ of the variability in $15 \mathrm{D}$ scores, and $25 \%$ of the variability in EQ-VAS scores.

Cox regression analysis showed that mortality was associated with EQ-5D (hazard ratio $=0.16, P=0.016$ ) (Table 6).

\section{Discussion}

We found that the frequencies of pain, fatigue, and depression were high. Most patients with one of these symptoms had at least one of the other two. The most frequent cluster of symptoms was the presence of both pain and fatigue, followed by all three symptoms, whereas depression and pain without fatigue was rare.

Regression analysis showed that HRQoL, as measured by EQ-5D, was highly associated with depression, pain, and functional state, but not fatigue. In contrast, previous studies have disclosed association between HRQoL and fatigue in stroke patients. ${ }^{20}$ Recent studies have shown that fatigue is an important symptom among some stroke patients. ${ }^{1,5}$ Our findings indicate that EQ-5D overlooks this important symptom and demonstrates how difficult it can be to study fatigue if 
Table 4 Linear regression with EQ-VAS, EQ-5D, and I5D as dependent variables on follow-up in patients with cerebral infarction

\begin{tabular}{|c|c|c|c|c|c|c|}
\hline & \multicolumn{2}{|l|}{ EQ-VAS } & \multicolumn{2}{|l|}{ EQ-5D } & \multicolumn{2}{|l|}{ I5D } \\
\hline & Partial correlation & $P$-value & Partial correlation & $P$-value & Partial correlation & $P$-value \\
\hline Sex & 0.05 & 0.52 & 0.01 & 0.93 & 0.02 & 0.76 \\
\hline Age & -0.03 & 0.64 & 0.03 & 0.64 & -0.15 & 0.04 \\
\hline Pain scale & -0.16 & 0.03 & -0.48 & $<0.001$ & -0.31 & $<0.001$ \\
\hline HADS-D & -0.18 & 0.01 & -0.21 & 0.004 & -0.50 & $<0.001$ \\
\hline FSS & -0.44 & $<0.001$ & -0.12 & 0.10 & -0.34 & $<0.001$ \\
\hline Barthel Index score & 0.37 & $<0.001$ & 0.55 & $<0.001$ & 0.52 & $<0.001$ \\
\hline Sleep disturbances & -0.04 & 0.58 & -0.01 & 0.87 & -0.37 & $<0.001$ \\
\hline
\end{tabular}

Abbreviations: EQ-VAS, EuroQol Visual Analogue Scale; EQ-5D, EuroQol; HADS-D, Depression Subscale of the Hospital Anxiety and Depression Scale; FSS, Fatigue Severity Scale; I5D, a generic instrument of health-related quality of life.

an inadequate instrument is used. Others have questioned whether EQ-5D is sensitive enough to detect clinically relevant differences in HRQoL between patient groups. ${ }^{21,22}$ However, two important reasons for using EQ-5D are the ability to transform the score into quality-adjusted life years and that the scale takes a short time to complete. ${ }^{23}$ The mean EQ-5D was lower among our patients than normative data from England ( 0.70 versus $0.78, P<0.001){ }^{24}$

We found that fatigue, depression, pain, functional state, and sleeping disorder, on followup, accounted for up to $83 \%$ of the variability in HRQoL, depending on which HRQoL assessment was used. Another analysis showed that age, depression prior to the index stroke, stroke prior to the index stroke, functional state one week after onset of the index stroke, and smoking prior to the index stroke accounted for about a third of the variation in HRQoL on followup. Furthermore, regression analysis showed that increasing frequency of pain, fatigue, and depression symptoms in each patient was highly associated with worse HRQoL. Thus, co-occurring symptoms adversely affected HRQoL to a large extent.

The optimal treatment of these symptom clusters may be challenging. Although the present study did not assess treatment, it seems prudent to evaluate which symptom constitutes the greatest burden. If depression is significant, then antidepressive treatment may alleviate depression, as well as fatigue and pain. Likewise, if pain dominates, then careful investigation of the cause of pain and institution of appropriate analgesic treatment may reduce pain, as well as accompanying fatigue and depression. In some patients, fatigue is associated with sleeping problems, and appropriate treatment of insomnia may reduce fatigue. Some studies indicate that fatigue is associated with lesion in the brainstem. ${ }^{1,5}$ Among these patients, treatment of fatigue may be particularly challenging. However, even among these patients, care should be taken to disclose possible depression, pain, and sleeping disturbances. Neither should one forget the possibility of fatigue as a side effect of medication. Our study shows that treatment of these symptoms may have a potentially large effect on HRQoL.

Through Cox regression analysis, even after adjusting for age and functional state, we found that low HRQoL was associated with higher subsequent mortality. Others have found HRQoL to be associated with long-term mortality in patients with cancer ${ }^{25}$ and after cardiac surgery. ${ }^{26}$ Self-rated HRQoL in large studies, including healthy persons, also has been shown to be associated with future mortality. ${ }^{27,28}$ These studies highlight the importance of people's health rating of HRQoL when evaluating risk of premature mortality and the need for secondary preventive treatment.

The strength of the present study is that patients were investigated with validated instruments for different symptoms. A weakness is that the response rate was only $61 \%$,

Table 5 Linear regression with EQ-VAS, EQ-5D, and I5D as dependent variables and prognostic variables known during hospital stay

\begin{tabular}{|c|c|c|c|c|c|c|}
\hline & \multicolumn{2}{|l|}{ EQ-VAS } & \multicolumn{2}{|l|}{ EQ-5D } & \multicolumn{2}{|l|}{ I5D } \\
\hline & Partial correlation & $P$-value & Partial correlation & $P$-value & Partial correlation & $P$-value \\
\hline Sex & -0.04 & 0.54 & 0.12 & 0.10 & -0.09 & 0.23 \\
\hline Age & -0.15 & 0.03 & -0.17 & 0.02 & -0.22 & 0.002 \\
\hline Prior depression & -0.32 & $<0.001$ & -0.33 & $<0.001$ & -0.40 & $<0.001$ \\
\hline Prior stroke & -0.12 & 0.08 & -0.13 & 0.06 & -0.15 & 0.04 \\
\hline Barthel score day 7 & 0.27 & $<0.001$ & 0.45 & $<0.001$ & 0.31 & $<0.001$ \\
\hline Smoking & -0.19 & 0.006 & -0.23 & $<0.001$ & -0.14 & 0.05 \\
\hline
\end{tabular}

Abbreviations: EQ-VAS, EuroQol Visual Analog Scale; EQ-5D, EuroQol. 
Table 6 Cox regression analysis including measure of quality of life

\begin{tabular}{llll}
\hline & Hazard ratio & 95\% confidence interval & $P$-value \\
\hline EQ-5D & 0.16 & $0.04-0.7$ & 0.018 \\
Age & 1.08 & $1.03-1.12$ & 0.001 \\
Sex & 0.55 & $0.23-1.3$ & 0.18 \\
Barthel Index & 0.99 & $0.97-1.0$ & 0.16 \\
\hline
\end{tabular}

Abbreviation: EQ-5D, EuroQol.

and complete data were obtained from $55 \%$. However, this is compatible with other studies based on postal questionnaires. We have reported previously that $82 \%$ of patients with cerebral infarction were alive one year after stroke onset. ${ }^{29}$ It is likely that the responding patients, on average, had better HRQoL than nonresponding patients, because non-responders on average had more severe stroke events. Thus, the reported frequencies of pain, fatigue, and depression were likely lower than among all stroke patients combined. The use of VAS scales in stroke patients has raised concern among some researchers, due to perceptual and cognitive deficits. ${ }^{30}$ However, as shown in Table 3, the differences between EQ-VAS and EQ-5D or $15 \mathrm{D}$ were minor. Another weakness is that we did not inquire about stroke-related pain. EQ-5D includes questions about pain and depression, and 15D about depression and fatigue, and this may account for some of the correlations between pain, depression, and fatigue and the HRQoL scores. However, the high correlation between these three symptoms and EQ-VAS indicates that our findings are relevant.

Future studies of HRQoL in stroke patients should focus on the cause of pain and better evaluation of sleep disturbances. The relationship between anxiety, cognitive deficits, and HRQoL should also be addressed in future research.

In conclusion, pain, fatigue, or depression symptoms were common in this sample of stroke patients and, to a large extent, determined the patients' quality of life.

\section{Disclosure}

The authors report no conflicts of interest in this work.

\section{References}

1. Staub F, Bogousslavsky J. Fatigue after stroke: a major but neglected issue. Cerebrovasc Dis. 2001;12(2):75-81.

2. Henon H. Pain after stroke: a neglected issue. J Neurol Neurosurg Psychiatry. 2006;77(5):569.

3. Kotila M, Numminen H, Waltimo O, Kaste M. Depression after stroke: results of the FINNSTROKE Study. Stroke. 1998;29(2):368-372.

4. Naess H, Nyland HI, Thomassen L, Aarseth J, Myhr KM. Mild depression in young adults with cerebral infarction at long-term follow-up: a population-based study. Eur J Neurol. 2005;12(3):194-198.

5. Naess H, Nyland HI, Thomassen L, Aarseth J, Myhr KM. Fatigue at longterm follow-up in young adults with cerebral infarction. Cerebrovasc Dis. 2005;20(4):245-250.
6. Glader EL, Stegmayr B, Asplund K. Poststroke fatigue: a 2-year follow-up study of stroke patients in Sweden. Stroke. 2002;33(5): 1327-1333.

7. Jonsson AC, Lindgren I, Hallstrom B, Norrving B, Lindgren A. Prevalence and intensity of pain after stroke: a population based study focusing on patients' perspectives. J Neurol Neurosurg Psychiatry. 2006;77(5):590-595.

8. Langhorne P, Stott DJ, Robertson L, et al. Medical complications after stroke: a multicenter study. Stroke. 2000;31(6):1223-1229.

9. Lundstrom E, Smits A, Terent A, Borg J. Risk factors for strokerelated pain 1 year after first-ever stroke. Eur J Neurol. 2009;16(2): 188-193.

10. Kim HJ, McGuire DB, Tulman L, Barsevick AM. Symptom clusters: concept analysis and clinical implications for cancer nursing. Cancer Nurs. 2005;28(4):270-282; quiz 83-84.

11. Reyes-Gibby CC, Aday LA, Anderson KO, Mendoza TR, Cleeland CS. Pain, depression, and fatigue in community-dwelling adults with and without a history of cancer. J Pain Symptom Manage. 2006;32(2): $118-128$.

12. Johnson CJ, Kittner SJ, McCarter RJ, et al. Interrater reliability of an etiologic classification of ischemic stroke. Stroke. 1995;26(1): $46-51$.

13. Adams HP Jr, Bendixen BH, Kappelle LJ, et al. Classification of subtype of acute ischemic stroke: definitions for use in a multicenter clinical trial. Trial of Org 10172 in Acute Stroke Treatment. Stroke. 1993;24(1): $35-41$.

14. Schwartz JE, Jandorf L, Krupp LB. The measurement of fatigue: a new instrument. J Psychosom Res. 1993;37(7):753-762.

15. Zigmond AS, Snaith RP. The Hospital Anxiety and Depression Scale. Acta Psychiatr Scand. 1983;67(6):361-370.

16. Tellez N, Rio J, Tintore M, Nos C, Galan I, Montalban X. Does the Modified Fatigue Impact Scale offer a more comprehensive assessment of fatigue in MS? Mult Scler. 2005;11(2):198-202.

17. Valko PO, Bassetti CL, Bloch KE, Held U, Baumann CR. Validation of the fatigue severity scale in a Swiss cohort. Sleep. 2008;31(11):1601-1607.

18. Jorngarden A, Wettergen L, von Essen L. Measuring health-related quality of life in adolescents and young adults: Swedish normative data for the SF-36 and the HADS, and the influence of age, gender, and method of administration. Health Qual Life Outcomes. 2006;4:91.

19. Sintonen H. The 15-D measure of health related quality of life. II. Feasibility, reliability and validity of its valuation system. Centre for Health Program Evaluation. 1995; Working Paper 42:1-27.

20. van de Port IG, Kwakkel G, Schepers VP, Heinemans CT, Lindeman E. Is fatigue an independent factor associated with activities of daily living, instrumental activities of daily living and health-related quality of life in chronic stroke? Cerebrovasc Dis. 2007;23(1):40-45.

21. Anderson RT, Aaronson NK, Bullinger M, McBee WL. A review of the progress towards developing health-related quality-of-life instruments for international clinical studies and outcomes research. Pharmacoeconomics. 1996;10(4):336-355.

22. Bradley C. Importance of differentiating health status from quality of life. Lancet. 2001;357(9249):7-8.

23. RedekopWK, Koopmanschap MA, StolkRP, Rutten GE, WolffenbuttelBH, Niessen LW. Health-related quality of life and treatment satisfaction in Dutch patients with type 2 diabetes. Diabetes Care. 2002;25(3): 458-463.

24. Kind P, Hardman G, Macran S. UK Population Norms for EQ-5D. York Centre for Health Economics, Discussion Paper, University of New York; 1999:172.

25. Shadbolt B, Barresi J, Craft P. Self-rated health as a predictor of survival among patients with advanced cancer. J Clin Oncol. 2002;20(10):2514-2519.

26. Rumsfeld JS, MaWhinney S, McCarthy M Jr, et al. Health-related quality of life as a predictor of mortality following coronary artery bypass graft surgery. Participants of the Department of Veterans Affairs Cooperative Study Group on Processes, Structures, and Outcomes of Care in Cardiac Surgery. JAMA. 1999;281(14):1298-1303. 
27. Idler EL, Kasl S. Health perceptions and survival: do global evaluations of health status really predict mortality? J Gerontol. 1991;46(2): S55-S65.

28. Nielsen AB, Siersma V, Hiort LC, Drivsholm T, Kreiner S, Hollnagel H. Self-rated general health among 40-year-old Danes and its association with all-cause mortality at 10-, 20-, and 29 years' follow-up. Scand J Public Health. 2008;36(1):3-11.
29. Naess H, Waje-Andreassen U, Brogger J, Thomassen L. Pasienter med akutt hjerneinfarkt innlagt i slagenhet [Patients with acute cerebral infarction admitted to stroke unit]. Tidsskr Nor Laegeforen. 2011;131(8):814-818. Norwegian.

30. Price CIM, Curless RH, Rodgers H. Can stroke patients use visual analogue scales? Stroke. 1999;30(7):1357-1361.

\section{Publish your work in this journal}

Vascular Health and Risk Management is an international, peerreviewed journal of therapeutics and risk management, focusing on concise rapid reporting of clinical studies on the processes involved in the maintenance of vascular health; the monitoring, prevention and treatment of vascular disease and its sequelae; and the involvement of metabolic disorders, particularly diabetes. This journal is indexed on PubMed Central and MedLine. The manuscript management system is completely online and includes a very quick and fair peer-review system, which is all easy to use. Visit http://www.dovepress.com/ testimonials.php to read real quotes from published authors.

Submit your manuscript here: http://www.dovepress.com/vascular-health-and-risk-management-journal 